\title{
Airway cells from atopic asthmatics exposed to ozone display an enhanced innate immune gene profile
}

\author{
Michelle Hernandez, MD ${ }^{a, b}$, Willie June Brickey, PhD $^{c}$, Neil E. Alexis N, PhD ${ }^{a, b}$, Rebecca C. \\ Fry, PhD ${ }^{d}$, Julia E. Rager, MS ${ }^{d}$, Baiming Zhou, MS ${ }^{e}$, Jenny PY Ting, PhD $^{e}$, Haibo Zhou, \\ PhD $^{\mathrm{a}, \mathrm{e},{ }^{*} \text {, and David B. Peden, MD,MS }}{ }^{\mathrm{a}, \mathrm{b}, \mathrm{c},{ }^{*}}$ \\ ${ }^{a}$ Center for Environmental Medicine, Asthma and Lung Biology The University of North Carolina \\ at Chapel Hill School of Medicine Chapel Hill, North Carolina \\ ${ }^{b}$ Department of Pediatrics The University of North Carolina at Chapel Hill School of Medicine \\ Chapel Hill, North Carolina \\ 'Department of Microbiology and Immunology The University of North Carolina at Chapel Hill \\ School of Medicine Chapel Hill, North Carolina \\ dEnvironmental Sciences \& Engineering, The Gillings School of Global Public Health \\ eBiostatistics, The Gillings School of Global Public Health
}

\section{Capsule Summary}

This study identifies transcriptional phenotypes of sputum samples from normal volunteers and atopic asthmatics exposed to ozone. Network analyses suggest that asthmatics elevate immune signaling following oxidative stress, while nonasthmatics attempt to mitigate the ozone-induced response.

\section{Keywords}

Asthma; Ozone; Induced Sputum; Profiling; Oxidative Stress

\begin{abstract}
Respiratory complications caused by ozone $\left(\mathrm{O}_{3}\right)$ represent a significant public health burden ${ }^{1-4}$. Ozone and a range of other pollutants are thought to exert their effects via oxidative stress responses in the lower airway. Despite studies suggesting that pulmonary oxidative insults by air pollutants lead to deleterious health outcomes, treatment options for environmentally-induced oxidative stress are limited, partially due to the lack of understanding of exactly how these pollutants affect susceptible populations.
\end{abstract}

\footnotetext{
(C) 2011 American Academy of Allergy, Asthma and Immunology. Published by Mosby, Inc. All rights reserved

Corresponding Author: Michelle L. Hernandez, MD Center for Environmental Medicine, Asthma and Lung Biology 104 Mason Farm Road UNC School of Medicine Chapel Hill, NC 27516 Michelle_Hernandez@med.unc.edu phone 919-843-5383 fax 919-966-9863.

These authors contributed equally to this effort as senior authors

Publisher's Disclaimer: This is a PDF file of an unedited manuscript that has been accepted for publication. As a service to our customers we are providing this early version of the manuscript. The manuscript will undergo copyediting, typesetting, and review of the resulting proof before it is published in its final citable form. Please note that during the production process errors may be discovered which could affect the content, and all legal disclaimers that apply to the journal pertain.

Disclosures: N. E. Alexis has contracts with Centocor Pharmacueticals, GlaxoSmithKline and MedImmune. D. B. Peden has been a consultant to GlaxoSmithKline and Aquinox Pharmaceuticals and a contract with MedImmune. J. PY. Ting had a one-year contract with GlaxoSmithKline (Philadelphia). The rest of the authors have declared that they have no conflicts of interest.
} 
Our group recently reported that atopic asthmatics (AA) had enhanced sputum inflammatory responses compared to normal volunteers (NV) after a 2 hour, 0.4 ppm $\mathrm{O}_{3}$ exposure, characterized by increases in macrophage TLR 4 expression and concentrations of IL- $1 \beta$, IL-6, and IL-8 in sputum samples ${ }^{5}$. This report expands on those results by examining gene expression profiles of sputum inflammatory cells from NV and AA volunteers as a means of identifying additional mechanisms that may explain the differences in inflammatory response between these two cohorts, and to confirm the airway inflammatory phenotype in a larger cohort of AA and NV.

Subject recruitment, sample collection and analysis techniques are identical to those we have recently reported ${ }^{5}$. Demographic data from a total of 51 subjects (34 NV, 17 AA) are presented in Table I. Statistical tests include paired t-tests to assess a specific cohort response to $\mathrm{O}_{3}$ for cell differentials; non-parametric paired Wilcoxon signed rank test to assess $\mathrm{O}_{3}$ responses for induced sputum cytokines; and non-parametric $\mathrm{t}$ tests (MannWhitney Test) to examine baseline differences in cytokines or cell differentials between AA and NV.

Data for induced sputum cell differentials and cytokines from $9 \mathrm{NV}$ and $6 \mathrm{AA}$ were added to our previously published cohort ${ }^{5}$. The composition of sputum cellularity was similar between the two cohorts, with the exception of increased sputum eosinophils in the AA cohort at baseline compared to NV (Table I). AA continued to show evidence of increased levels of IL-1 $\beta$, IL-6, and IL-8 after $\mathrm{O}_{3}$ exposure (Table I), with reduced levels of IL-10 and increased levels of IL- $1 \beta$ and IL-8 at baseline. The larger sample size supports the notion that despite similarities in sputum cellularity, AA display increased levels of airway proinflammatory cytokines after $\mathrm{O}_{3}$ exposure compared to NV.

Of the 51 volunteers described above, adequate mRNA was recovered from $18 \mathrm{NV}$ and 13 AA for microarray analysis using a custom-designed microarray representing more than 2000 immune response gene targets ${ }^{6}$. Raw expression data were first normalized using the down-weighting loess fit ${ }^{7}$ to remove systematic ratio-intensity dependence. The normalized red/green expression ratio was $\log _{2}$ transformed and uploaded to Significant Analysis of Microarrays software package ${ }^{8}$ in R (version 2.10 ) to identify differentially expressed genes. To control for multiple comparisons, we used false discovery rate (FDR), estimated by 5000 permutations for each target.

At FDR $=0.05$, we found a total of 102 genes that showed differential expression after $\mathrm{O}_{3}$ exposure compared to baseline conditions (Figure 1A). Fifty-five genes had significant expression changes with $\mathrm{O}_{3}$ exposure in NV; 47 genes had significant changes in gene expression with $\mathrm{O}_{3}$ exposure in AA. Only one gene overlapped between the two cohorts, aurora kinase $\mathrm{B}$.

In order to identify potential biological pathways affected by $\mathrm{O}_{3}$ exposure, the differentially expressed gene profiles for each cohort were overlaid onto protein-protein maps enabled through the Ingenuity Pathways' Knowledge Base ${ }^{6}$. Statistical significance of each network was calculated using a Fischer's exact test. This test generated a p-value signifying the probability that each network was associated with the mRNA targets by chance alone.

For each of the two gene lists, significant networks were identified. The set of 55 genes that showed $\mathrm{O}_{3}$-induced changes in $\mathrm{NV}$ could be integrated into four networks ranging in significance from $10^{-16}$ to $10^{-44}$. The most significant $\mathrm{NV}$ network is enriched for proteins involved in the ERBB2 (also known as HER-2) pathway, with most of the signaling predicted to be downregulated in this pathway (Table E1). The 47 differentially expressed genes associated with the $\mathrm{O}_{3}$ challenge in AA were integrated into four networks ranging in 
significance from $10^{-9}$ to $10^{-45}$. The most significant AA network is enriched for genes involved in immune response signaling such as NFKB (Table E2).

Of the genes that showed the most statistically significant changes in gene expression, confirmatory quantitative PCR was performed on induced sputum mRNA from $6 \mathrm{NV}$ and 8 AA using previously published methods ${ }^{9}$. A comparative CT approach was used to discern changes in relative expression due to $\mathrm{O}_{3}$ with $\beta$-Actin as the housekeeping gene and pre- $\mathrm{O}_{3}$ as untreated control (Figure 1B).

The expression levels of HER-2 pathway genes such as ERBB2, cyclin D1 (CCND1), and matrix metalloprotease II (MMP2) were significantly increased in AA compared to NV (Figure 1B). Furthermore, AA had significantly increased expression of genes involved in cellular detoxification after oxidative stress (GPX3, GSTM4, NQO1) and those involved in neutrophil oxidative burst (NCF2) compared to NV (Figure 1B). This is consistent with the idea that asthmatics have a differential oxidative stress response following $\mathrm{O}_{3}$ exposure compared to NV. The expression levels of several innate immune genes, such as the MHC-II molecule $H L A-D P A 1$, the integrin $I C A M-1$, and the pro-inflammatory cytokines $I L-6, I L-8$, $I L-18$, and $T N F \alpha$ were significantly increased in AA compared to NV upon exposure to $\mathrm{O}_{3}$ (Figure 1B).

In summary, gene expression profiles for sputum cells are distinctly different in NV and AA despite similar neutrophil and macrophage proportions after acute $\mathrm{O}_{3}$ exposure. Compared to $\mathrm{NV}$, AA showed increased immune signaling, elevated pro-inflammatory cytokines, and up-regulated expression of the HER-2 gene network, indicative of enhanced epithelial cell proliferation. These data suggest that unlike NV, AA cannot limit epithelial cell proliferative responses following $\mathrm{O}_{3}$-induced oxidative stress. HER-2 blockade has been found to reduce lung fibrosis and remodeling in a model of bleomycin-induced lung injury ${ }^{10}$. Limitations of this study include small sample size and mixed sputum cellularity that prevented cell specific determination of oxidative stress responses in these populations. Future studies will focus on dissecting the contributions of distinct cell types on determining responses to $\mathrm{O}_{3}$ in a larger cohort of individuals, as well as including baseline measures of inflammation. This information is important for the judicious development of therapeutics that will prevent or reduce the harmful effects of oxidant lung injury.

\section{Acknowledgments}

Funding Sources: MLH is supported by NIH KL2RR025746; WJB, NEA, JPYT, and DBP are supported by NIAID U19AI077437; RCF and JR are supported by P30ES010126. This work was also funded by CR 83346301 from the US Environmental Protection Agency.

\section{Abbreviations}

\begin{tabular}{|c|c|}
\hline $\mathbf{O}_{3}$ & Ozone \\
\hline $\mathbf{A A}$ & atopic asthmatic \\
\hline NV & normal volunteer \\
\hline ppm & part per million \\
\hline IL-1 $\beta$ & interleukin -1 beta \\
\hline IL-8 & interleukin-8 \\
\hline IL-6 & interleukin-6 \\
\hline TLR4 & toll-like receptor 4 \\
\hline
\end{tabular}


TLR2 toll-like receptor 2

TNFa tumor necrosis factor alpha

ICAM1 Inter-Cellular Adhesion Molecule 1

HLA-DP1 major histocompatibility complex, class II, DP

GSTM4 glutathione S-transferase mu 4

GPX3 glutathione peroxidase 3

NCF2 neutrophil cytosolic factor 2

ERBB2 v-erb-b2 erythroblastic leukemia viral oncogene homolog 2, neuro/ glioblastoma derived oncogene homolog (avian)

CCND1 cyclin D-1

MMP2 matrix metalloprotease II

NQO1 NAD(P)H dehydrogenase, quinone 1

\section{References}

1. Bell ML, McDermott A, Zeger SL, Samet JM, Dominici F. Ozone and short-term mortality in 95 US urban communities, 1987-2000. JAMA. 2004; 292:2372-8. [PubMed: 15547165]

2. Chuang GC, Yang Z, Westbrook DG, Pompilius M, Ballinger CA, White CR, et al. Pulmonary ozone exposure induces vascular dysfunction, mitochondrial damage, and atherogenesis. Am J Physiol Lung Cell Mol Physiol. 2009; 297:L209-16. [PubMed: 19395667]

3. Jerrett M, Burnett RT, Pope CA 3rd, Ito K, Thurston G, Krewski D, et al. Long-term ozone exposure and mortality. N Engl J Med. 2009; 360:1085-95. [PubMed: 19279340]

4. Stafoggia M, Forastiere F, Faustini A, Biggeri A, Bisanti L, Cadum E, et al. Susceptibility factors to ozone-related mortality: a population-based case-crossover analysis. Am J Respir Crit Care Med. 2010; 182:376-84. [PubMed: 20339147]

5. Hernandez ML, Lay JC, Harris B, Esther CR Jr. Brickey WJ, Bromberg PA, et al. Atopic asthmatic subjects but not atopic subjects without asthma have enhanced inflammatory response to ozone. $\mathrm{J}$ Allergy Clin Immunol. 2010; 126:537-44. e1. [PubMed: 20816188]

6. Alexis NE, Brickey WJ, Lay JC, Wang Y, Roubey RA, Ting JP, et al. Development of an inhaled endotoxin challenge protocol for characterizing evoked cell surface phenotype and genomic responses of airway cells in allergic individuals. Ann Allergy Asthma Immunol. 2008; 100:206-15. [PubMed: 18426139]

7. Dudoit S, Yang YH, Callow MJ, Speed TP. Statistical methods for identifying differentially expressed genes in replicated cDNA microarray experiments. Statistica Sinica. 2002; 12:111-39.

8. Tusher VG, Tibshirani R, Chu G. Significance analysis of microarrays applied to the ionizing radiation response. Proc Natl Acad Sci U S A. 2001; 98:5116-21. [PubMed: 11309499]

9. Brickey WJ, Alexis NE, Hernandez ML, Reed W, Ting JP, Peden DB. Sputum inflammatory cells from patients with allergic rhinitis and asthma have decreased inflammasome gene expression. $\mathbf{J}$ Allergy Clin Immunol. 2011; 128:900-3. [PubMed: 21868073]

10. Faress JA, Nethery DE, Kern EF, Eisenberg R, Jacono FJ, Allen CL, et al. Bleomycin-induced pulmonary fibrosis is attenuated by a monoclonal antibody targeting HER2. J Appl Physiol. 2007; 103:2077-83. [PubMed: 17916677] 


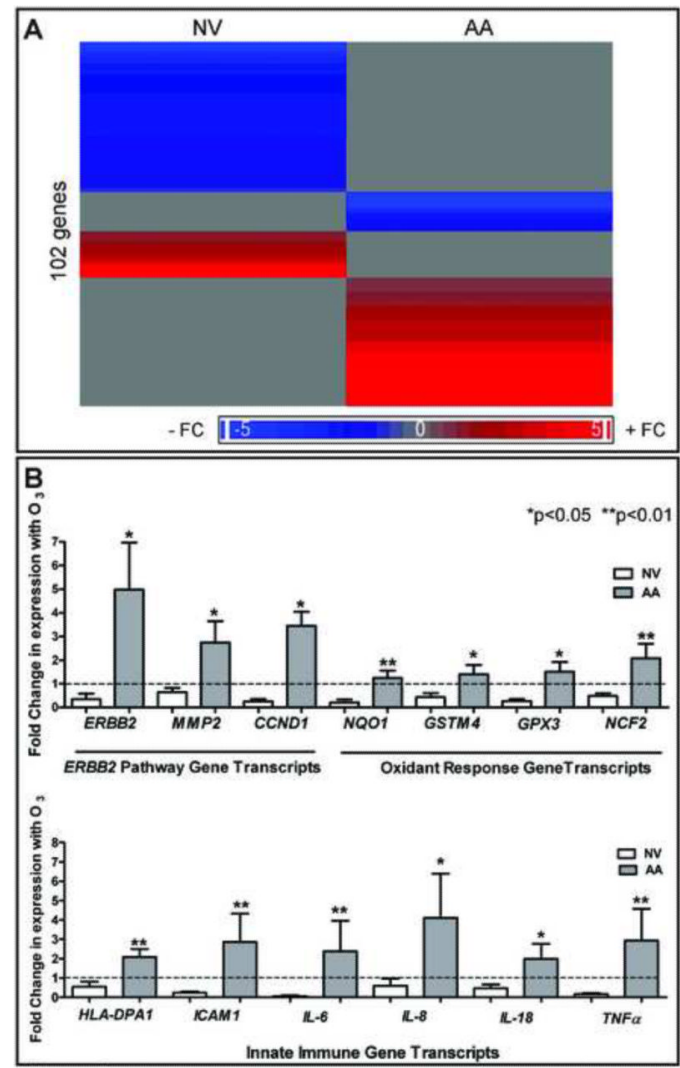

Figure 1. $\mathrm{O}_{3}$-induced transcript profiles in $\mathrm{NV}$ and AA

A) Heat map of $\mathrm{O}_{3}$-modulated genes in $\mathrm{NV}$ and AA with low (blue) and high (red) expression. B) Changes with $\mathrm{O}_{3}$ in PCR-amplified ERBB2 pathway, oxidant response and innate immune transcripts relative to $A C T B(n=6 \mathrm{NV}, 8 \mathrm{AA})$. Mean changes in gene expression with $\mathrm{O}_{3}( \pm \mathrm{SEM})$. Nonparametric t testing (Mann Whitney testing) was used to compare differences in NV and AA. 


\section{Table I}

Characteristics of Participants

\begin{tabular}{|c|c|c|}
\hline Clinical Characteristic & Normal Volunteer & Atopic Asthmatic \\
\hline$n$ & 34 & 17 \\
\hline Age (y), mean (SD) & $24.2(3.9)$ & 10 Female / 7 Male \\
\hline Gender & 20 Female / 14 Male & (5) \\
\hline Race & 27 White; 4 African American; 3 Asian & 13 White; 3 African American 1 Asian \\
\hline
\end{tabular}

\begin{tabular}{|c|c|c|c|c|}
\hline & Pre $\mathrm{O}_{3}$ & Post $\mathrm{O}_{3}$ & Pre $\mathrm{O}_{3}$ & Post $\mathrm{O}_{3}$ \\
\hline \multicolumn{5}{|l|}{ Induced Sputum Cellularity } \\
\hline$\%$ Neutrophils, Mean (SD) & $40.9(19.3)$ & $64.3(15.7)^{*}$ & $35.8(19.4)$ & $58.4(23.4)^{*}$ \\
\hline \% Eosinophils, Mean (SD) & $0.12(0.2)$ & $0.5(0.2)$ & $1.95(2)^{* *}$ & $2.9(4.7)$ \\
\hline$\%$ Macrophages, Mean (SD) & $55.6(18.7)$ & $32.1(14.8)$ & $59.6(19.7)$ & $34.2(20.7)$ \\
\hline \multicolumn{5}{|c|}{$\begin{array}{c}\text { Induced Sputum Cytokines (pg/ml } \\
\text { sputum) }\end{array}$} \\
\hline IL-1 $\beta$, Median $(25 \%-75 \%)$ & $208(162-691)$ & $221(77-475)$ & $648^{+}(244-1247)$ & $1121^{++}(295-2018)$ \\
\hline IL-8, Median (25\%-75\%) & 4694 (1892-11373) & $3622(837-14071)$ & $12496^{\wedge}(8347-25669)$ & $23278^{++}(7558-46020)$ \\
\hline IL-6, Median (25\%-75\%) & $110(46-172)$ & $123(39-233)$ & $32(18-138)$ & $139^{\#}(31-666)$ \\
\hline IL-10, Median (25\%-75\%) & $36(0-307)$ & $7(0-240)$ & $0 * *(0-6)$ & $0(0-53)$ \\
\hline
\end{tabular}

$\mathrm{p}<0.001$ comparing pre $\mathrm{O}_{3}$ to post $\mathrm{O}_{3}$ values

**

$\mathrm{p}<0.01$ comparing baseline values of $\mathrm{AA}$ to $\mathrm{NV}$

${ }_{\mathrm{p}}=0.03$ comparing baseline values of $\mathrm{AA}$ to $\mathrm{NV}$

${ }_{\mathrm{p}}^{++}=0.03$ comparing pre $\mathrm{O}_{3}$ to post $\mathrm{O}_{3}$ values

$\wedge$

$\mathrm{p}=0.02$ comparing baseline values of $\mathrm{AA}$ to $\mathrm{NV}$

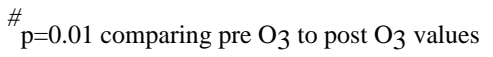

